Unfallchirurg 2015 • 118:6-6

DOI 10.1007/s00113-014-2728-7

Online publiziert: 26. Januar 2015

c) Springer-Verlag Berlin Heidelberg 2015

Schriftleitung Der Unfallchirurg

\title{
Die Herausgeber von Der Unfallchirurg danken den Gutachtern 2014
}

einem hohen Zeitaufwand meist am sogenannten Feierabend oder Wochenende verbunden. Im Jahr 2014 wurden in Der Unfallchirurg nur 10\% der angenommenen Artikel direkt publiziert, 58\% durchliefen eine, 22\% zwei und 10\% drei Revisionen! Die überwiegende Zahl der Autoren anerkannten und bedankte sich am Schluss für die sorgfältigen Verbesserungen durch die zwei anonym arbeitenden Gutachter, die jeweils Originalität und Aktualität, die Validität und die Plausibilität der Ergebnisse prüften, aber auch sehr detaillierte Hinweise zur graphischen und Textgestaltung gaben. Leider verbietet es der Grundsatz der Anonymität, pars pro toto einmal einen Text vor und nach Revision abzudrucken.

Jedenfalls hat sich das Prinzip des Review-Prozesses aus unserer Sicht bewährt. An der einseitigen Verblindung der Begutachtung wollen wir festhalten, weil sie den Gutachter schützt und „Wischi-waschi-Gefälligkeiten“ verhindert. Durch die 4-Augen-Bewertung, die Möglichkeit eines zusätzlichen Seniorgutachtens und die Herausgebertätigkeit beugen wir überzogenem Kritisieren, Verzögerungstaktik, Revierverhalten und anderem der Anonymität angelastetem Missbrauch vor.

„Peer review“ ist, so schreibt es das Deutsche Ärzteblatt (DÄ 109, Seite 900, Dez. 2012) ... wenig evaluiert, aber ... alternativlos. In diesem Sinne danken wir anlässlich dieser Ausgabe des Unfallchirurgen mit Originalarbeiten bewusst unseren Reviewern und hoffen weiter auf ihre gute Zuarbeit.

In gleichem Maß gilt unser Dank allen Herausgebern und Gutachtern, die im
Jahr 2014 an den interessanten Leitthemen unserer Zeitschrift mitgewirkt haben.

Für die Schriftleitung Der Unfallchirurg, Ihre

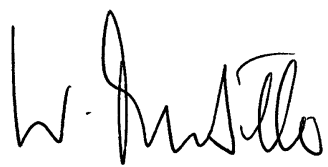

Prof. Dr. W. Mutschler

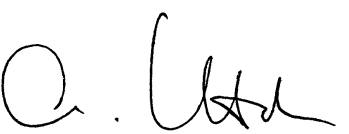

Prof. Dr. C. Krettek
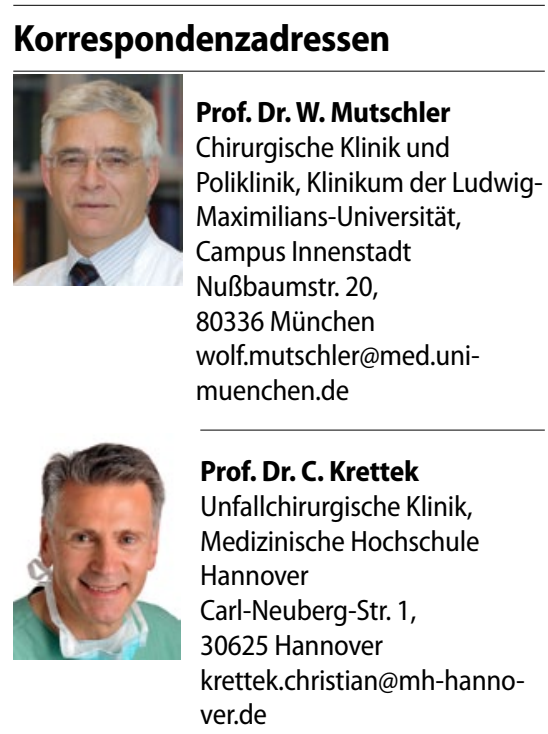

Einhaltung ethischer Richtlinien

Interessenkonflikt. W. Mutschler und C. Krettek geben an, dass kein Interessenkonflikt besteht. 